\title{
Fluorescent Tau-derived Peptide for Monitoring Microtubules in Living
}

\section{Cells}

Hiroshi Inaba, ${ }^{*[a, b]}$ Takahisa Yamamoto, ${ }^{[a]}$ Takashi Iwasaki, ${ }^{[c]}$ Arif Md. Rashedul Kabir, ${ }^{[\mathrm{d}]}$ Akira Kakugo, ${ }^{[\mathrm{d}, \mathrm{e}]}$ Kazuki Sada, ${ }^{[\mathrm{d}, \mathrm{e}]}$ and Kazunori Matsuura*[a,b]

[a] Department of Chemistry and Biotechnology, Graduate School of Engineering, Tottori University, Koyama-Minami 4-101, Tottori 680-8552, Japan.

[b] Centre for Research on Green Sustainable Chemistry, Tottori University, Tottori 680-8552, Japan.

[c] Department of Bioresources Science, Graduate School of Agricultural Sciences, Tottori University, Koyama-Minami 4-101, Tottori 680-8553, Japan.

[d] Faculty of Science, Hokkaido University, Kita 10 Nishi 8, Kita-ku, Sapporo 060-0810, Japan.

[e] Graduate School of Chemical Sciences and Engineering, Hokkaido University, Sapporo 0600810, Japan. 




Figure S1. Fluorescence spectra of $1 \mu \mathrm{M}$ TP-TMR (red) and 5(6)-carboxytetramethylrhodamine (TMR-COOH, black) in BRB80 buffer (80 mM PIPES pH 6.9, $1.0 \mathrm{mM} \mathrm{MgCl} 2,1.0$ mM EGTA). Excitation at $550 \mathrm{~nm}$.

\section{TP-TMR/Hoechst 33342}

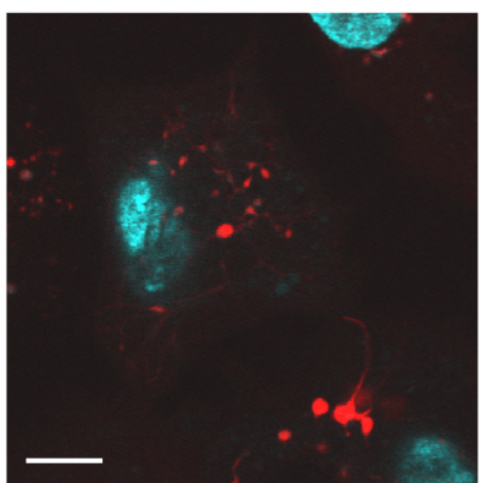

Figure S2. CLSM images of HepG2 cells incubated with $4 \mu \mathrm{M}$ TP-TMR for $6 \mathrm{~h}$ at $37^{\circ} \mathrm{C}$ under 5\% $\mathrm{CO}_{2}$ (scale bar: $10 \mu \mathrm{m}$ ). Cell nuclei were stained by Hoechst 33342. 
(a) $1 \mathrm{~h}$

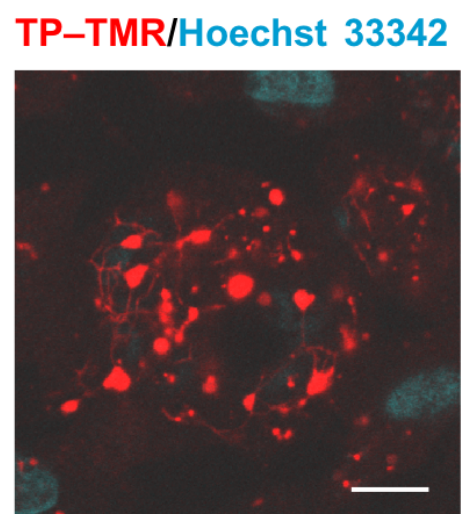

(b) $3 \mathrm{~h}$

\section{TP-TMR/Hoechst 33342}

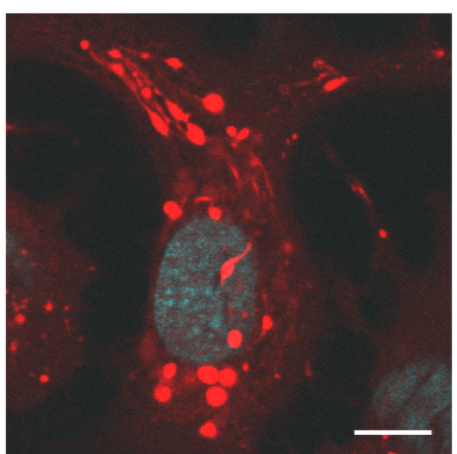

Figure S3. CLSM images of HepG2 cells incubated with $10 \mu \mathrm{M}$ TP-TMR for (a) $1 \mathrm{~h}$ and (b) $3 \mathrm{~h}$ at $37^{\circ} \mathrm{C}$ under $5 \% \mathrm{CO}_{2}$ (scale bar: $10 \mu \mathrm{m}$ ). Cell nuclei were stained by Hoechst 33342 .
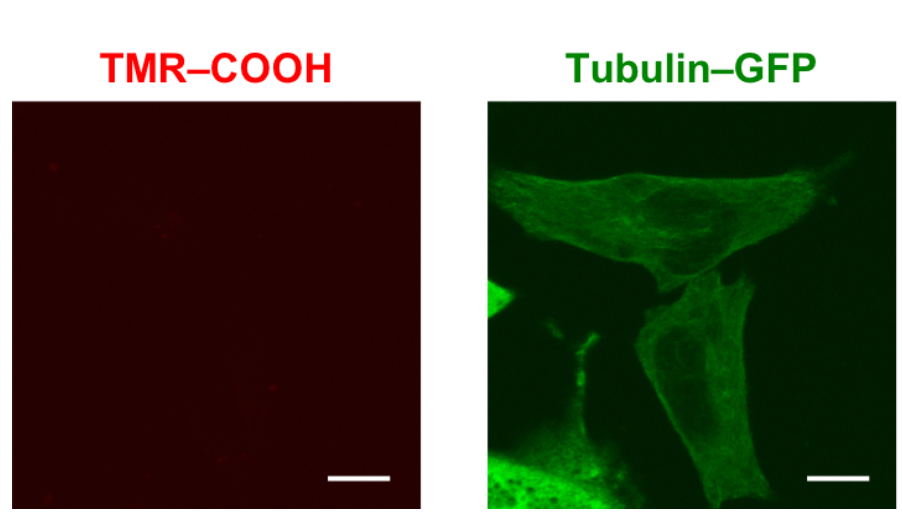

TMR-COOH/Tubulin-GFP

/Hoechst 33342

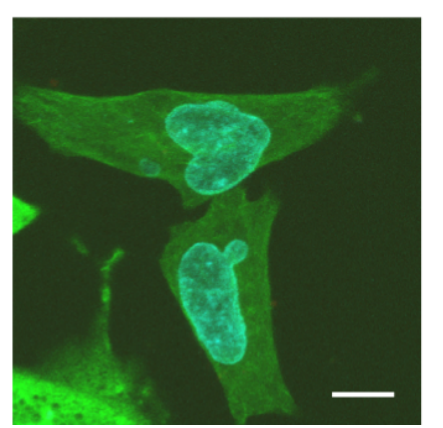

Figure S4. Confocal laser scanning microscopy (CLSM) images of HepG2 cells incubated with 10 $\mu \mathrm{M}$ TMR-COOH for $6 \mathrm{~h}$ at $37^{\circ} \mathrm{C}$ under $5 \% \mathrm{CO}_{2}$ (scale bar: $10 \mu \mathrm{m}$ ). Tubulin-GFP was expressed before incubation with TMR-COOH. Cell nuclei were stained by Hoechst 33342. 
TP-TMR/Hoechst 33342

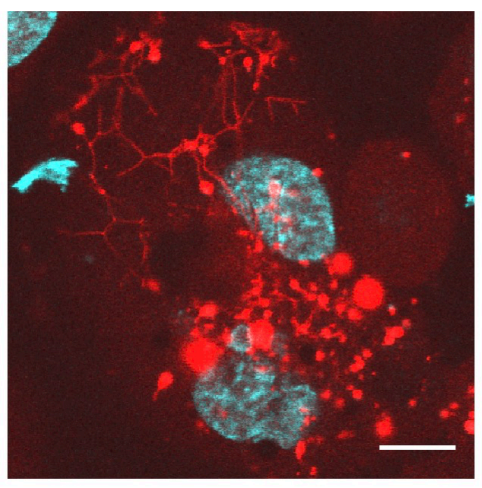

Figure S5. A CLSM image of HepG2 cells incubated with $10 \mu \mathrm{M}$ TP-TMR for $6 \mathrm{~h}$ at $37^{\circ} \mathrm{C}$ under $5 \% \mathrm{CO}_{2}$ and subsequent incubation for $24 \mathrm{~h}$ after washing (scale bar: $10 \mu \mathrm{m}$ ). Cell nuclei were stained by Hoechst 33342 .

(a) $37^{\circ} \mathrm{C}$

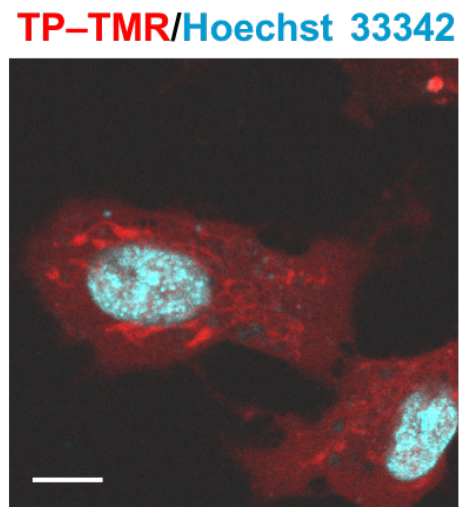

(b) $4^{\circ} \mathrm{C}$

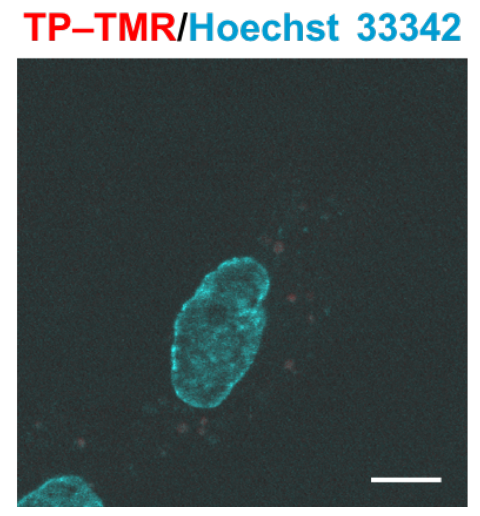

Figure S6. Temperature dependence of cellular uptake of TP-TMR. CLSM images of HepG2 cells incubated with $10 \mu \mathrm{M}$ TP-TMR for $3 \mathrm{~h}$ at (a) $37^{\circ} \mathrm{C}$ and (b) $4{ }^{\circ} \mathrm{C}$ (scale bars: $10 \mu \mathrm{m}$ ). Cell nuclei were stained by Hoechst 33342 . 
(a)

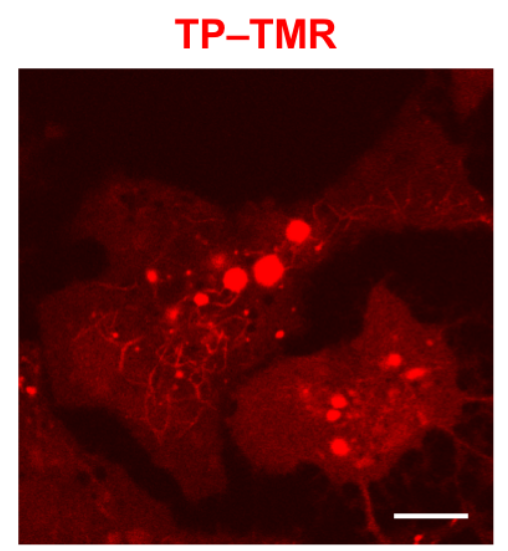

(c)

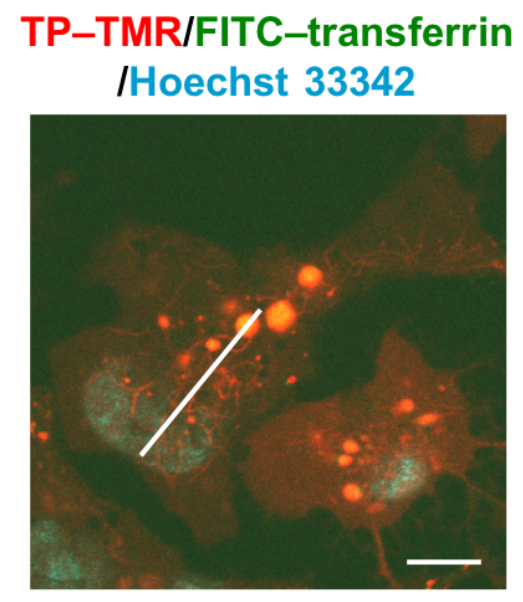

(b)

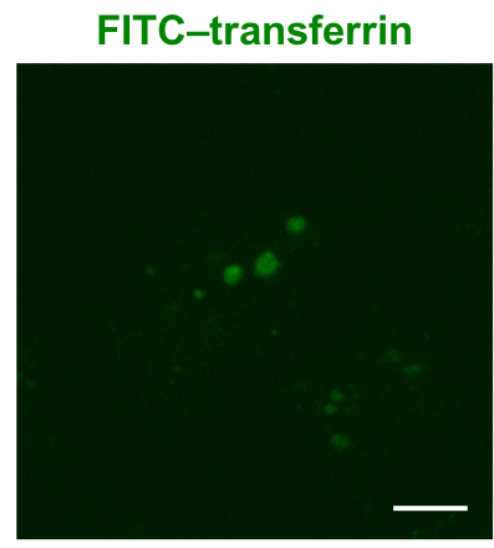

(d)

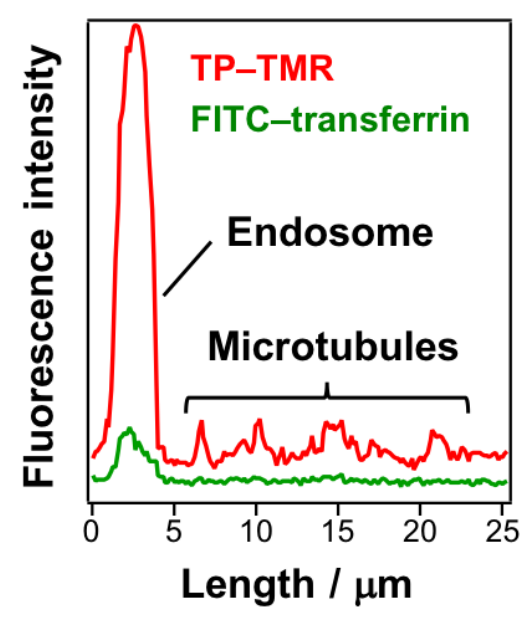

Figure S7. Evaluation of endosomal escape of TP-TMR. Channels for (a) TP-TMR, (b) FITCtransferrin, and (c) TP-TMR, FITC-transferrin, and Hoechst 33342 for CLSM images (scale bars: $10 \mu \mathrm{m})$. (d) Distribution of TP-TMR and FITC-transferrin was quantified by measuring fluorescence intensity in the line areas in the image (c). $10 \mu \mathrm{M}$ TP-TMR and $0.1 \mathrm{mg} / \mathrm{mL}$ FITCtransferrin were incubated with HepG2 cells for $6 \mathrm{~h}$ at $37^{\circ} \mathrm{C}$ under $5 \% \mathrm{CO}_{2}$. Cell nuclei were stained by Hoechst 33342 . 


\section{TP-TMR}

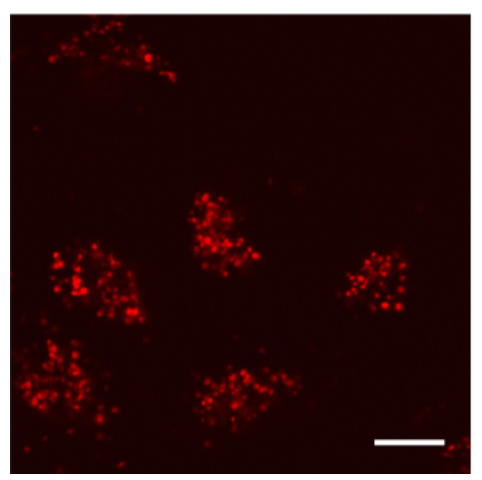

Tubulin-GFP

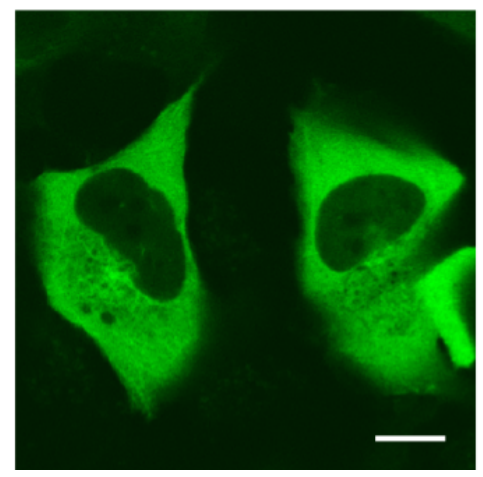

TP-TMR/Tubulin-GFP

/Hoechst 33342

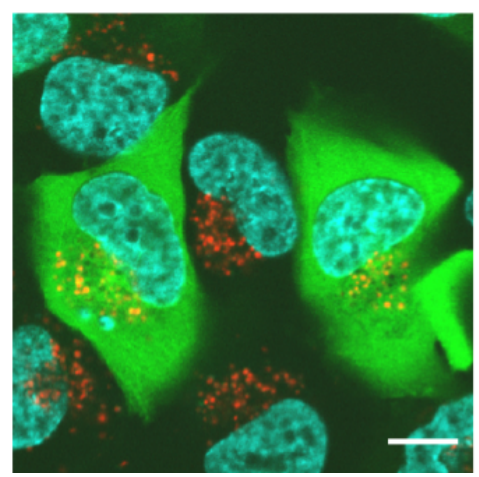

Figure S8. CLSM images of U251 cells incubated with $10 \mu \mathrm{M}$ TP-TMR for $6 \mathrm{~h}$ at $37^{\circ} \mathrm{C}$ under 5\% $\mathrm{CO}_{2}$ (scale bar: $10 \mu \mathrm{m}$ ). Tubulin-GFP was expressed before incubation with TP-TMR. Cell nuclei were stained by Hoechst 33342 .

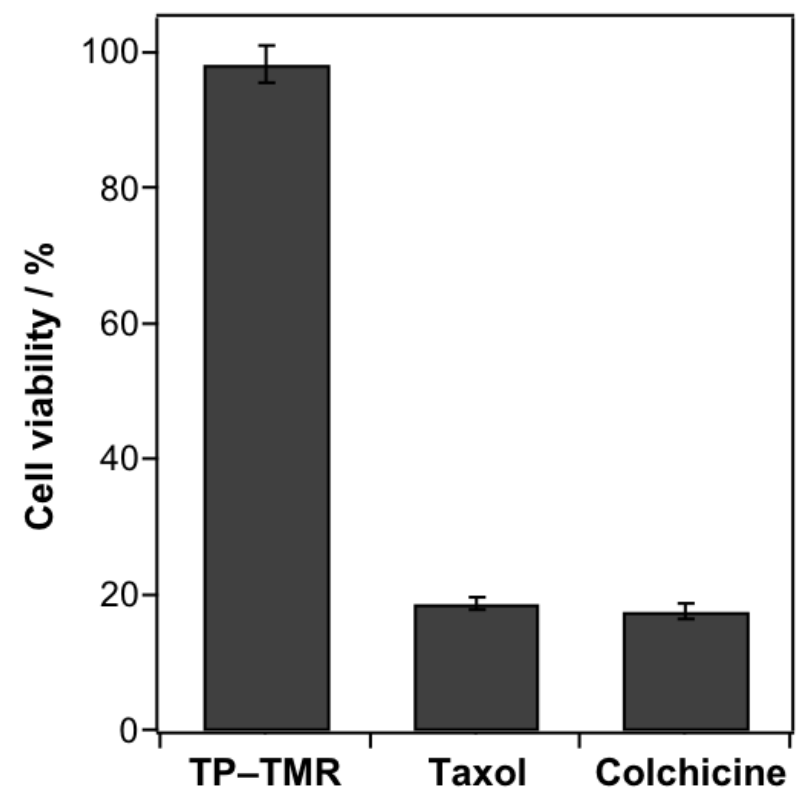

Figure S9. Cytotoxicity of TP-TMR against HepG2 cells for long incubation. HepG2 cells were incubated with $10 \mu \mathrm{M}$ TP-TMR, taxol, or colchicine for $72 \mathrm{~h}$ at $37^{\circ} \mathrm{C}$ under $5 \% \mathrm{CO}_{2}$. Cell viability was evaluated by the WST assay. The error bars represent standard deviation.

Movie S1. Cross sectional scans of HepG2 cells incubated with TP-TMR in Figure 2 acquired at different heights. Channels for TP-TMR and Hoechst 33342 were shown. 